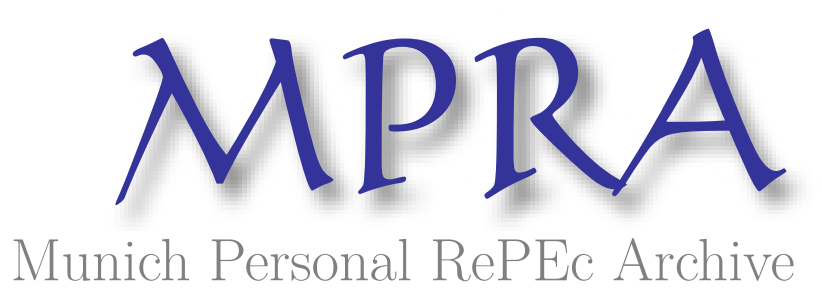

\title{
Does Competition Kill Ties?
}

Lai, Richard

Harvard Business School

28 March 2005

Online at https://mpra.ub.uni-muenchen.de/4759/

MPRA Paper No. 4759, posted 07 Sep 2007 UTC 


\title{
Does Competition Kill Ties?
}

\author{
Richard Lai ${ }^{1}$
}

First version: December 13, 2004

This version: March 28, 2005

Venture capital firms (VCs) form syndicates that compete to invest in deals. Does more competition makes it less likely that VCs will choose syndicate partners based on past ties? Using over 200,000 observations on how VCs choose each other in 572 biotech deals in Massachussetts from 1967 through 2004, I find the answer is: yes. The theory of embeddedness argues that past ties can explain the pattern of who works with who. I interpret my finding as a first step in demarcating when embeddedness might apply and when atomistic, calculative, economic forces might be a better explanation of who works with who. Practically, the finding could be an important piece of the puzzle of how VCs fund entrepreneurs in the latter's quest for growth.

\footnotetext{
${ }^{1}$ Harvard Business School, Morgan Hall 442A, Boston, tel: 617495 7228, email: rlai@hbs.edu. I am grateful for comments from Lee Fleming, Steve Kahl, Santiago Mingo, Renee Richardson, Mark Szigety, and Yanbo Wang. All errors are mine.
} 


\section{Does Competition Kill Ties?}

Venture capital firms (VCs) form syndicates that compete to invest in deals. Does more competition makes it less likely that VCs will choose syndicate partners based on past ties? I find that the answer is: yes.

This study arises from two motivations. The theoretical one is to explore the boundary of embeddedness. The theory predicts, among other things, that past ties explain current ones. One exposition (Granovetter, 1985) has been cited more than 1,840 times in less than 20 years. Still, the theory is silent on what happens when competition, the idol of American economics, shows up on stage. Does embeddedness reign only when competition is absent? My hypothesis is: When a party has to choose partners for a prospective transaction, more competition for the transaction reduces the odds that partners will be chosen based on past ties. One VC executive says in an interview for this work: "you'd walk over your grandmother if there's competition."

The second motivation is practical. The VC industry is a prodigious force in the U.S. Global Insight estimates that in 2004, V.C-funded entrepreneurial firms contribute 10.1 million jobs (9.4\% of private employment) and $\$ 1.8$ trillion in sales $(9.6 \%$ of company sales). From an entrepreneur's point of view, VC funding is one of the most important factors in the ability to scale up (Evans \& Jovanovic, 1989). Unlike many economic activities, VC investments are often undertaken in syndicates. Of the 81,512 rounds of investments identified in the Venture Economics dataset I have obtained, 56.7\% are by multiple VC firms. VCs work in syndicates to diversify their risks, by investing smaller amounts in more start-ups. Who they choose as partners is an intriguing issue. To understand VC activity, we have to understand ties.

In this paper, "ties" refers to horizontal ones, between two parties in the same syndicate. 
This is unlike vertical ties, like those between investor and investee, or supplier and customer, in which one party tries to extract as much surplus as possible from the other. And by "competition," I mean the contest of syndicates for the same goal (investment deal), not the bargaining between two parties in a vertical tie.

\section{THEORY}

I rely on three sources to build a simple theory of why and how competition affects ties. The first is induction from first-hand experience of fourteen years in the private equity industry. The second are unstructured, informal interviews with three $\mathrm{VC}^{2} \mathrm{~s}$ : (1) a global firm based in New York; (2) another based in Asia and is one of the largest VC and buy-out managers in the US and Europe, with over $\$ 5$ billion under management; and (3) a third based in the US. These interviews have been done between July and December 2004. The third source is the literatures from economics and sociology, which are good places to begin.

\section{Relation to Extant Literature}

There is abundant theoretical support for my hypothesis from the economics literature. Sub-fields are distinguished by the degree of competition assumed. It is a textbook assumption that the closer a market is to the perfect competition, the closer would transactions be based on optimizing economic considerations like prices, not social factors like ties.

More recently, behavioral economists (e.g.: Shleifer, 2004) argue that competition destroys the gentlemanly order that Hirschman (1982) calls doux commerce, that people follow the rules of the games, reciprocate, and trust each other, despite incentives to the

2 I use the abbreviation "VC" to mean "venture capital" or "venture capitalist" (as in venture capital firm). If the context is not clear, I revert to "VC firm" to refer to the latter. 
contrary . This also supports the hypothesis.

In the more specialized field of corporate finance, there is a literature on financial contracting that is also relevant. The basic argument is that principals are often vulnerable to agency problems. For example, banks are vulnerable to moral hazard problems since, given all else being equal, their borrower's would prefer not to transparent about their ability to repay loans (Bolton \& Scharfstein, 1996; Dewatripont \& Tirole, 1994). The more severe the agency problem, the more likely is that banks will keep borrowers on their toes, such as using shorter-term debt. In our setting, this is analogous to the lead VC keeping its usual syndicate partners on their toes by switching out of the relationships, especially when competition is severe and agency problems must be minimized.

Sociologists can be depended on for the same support, although the channel through which competition reduces the need for ties is strikingly different. The modern sociological explanation of who works with who may have started with Polanyi (1944), who argues that market structure is not an outcome of atomistic individuals, but of human institutions tied to the underlying social fabric. This is extended by Granovetter (1985), who argues that neoclassical, Hobbesian economic explanations are "undersocialized" and reformist economic ones such as Arrow's (1974) are "oversocialized." He proposes that economic action is embedded in "ongoing structures of social relations" such as past ties. This view is supported by many studies, in contexts such as immigrant enterprises (e.g.: Uzzi, 1997), alliances (e.g.: Gulati \& Gargiulo, 1999; Larson, 1992), investment banking relationships (Podolny, 1994), and day-care centers (Baum \& Oliver, 1992). Embeddedness is plainly valid. But embeddedness suggests that past ties predict present ties because "trust and power drive a wedge between interests and action." (Granovetter, 2000) In my formulation, competition tightens the link between interest (get the deal) and action (undertake a 
broader search for a syndicate partner), so that the same level of trust and power will be harder put to drive a wedge through between the two. Therefore, my hypothesis clarifies, not refutes, embeddedness, in the sense that it suggests that there is a limit to embeddedness. This stance is most consistent with more recent work, such as that by Uzzi, who argues that the "positive effects [of embeddedness] rise up to a threshold, however, after which embeddedness can derail economic performance by making firms vulnerable to exogenous shocks or insulating them from information that exists beyond their network." (1996) I interpret VCs' reduced reliance on ties as a move to avoid making themselves vulnerable in the way suggested by Uzzi.

From another stream of research, social exchange theory (e.g.: Blau, 1964; Emerson, 1972; Molm, Takahashi, \& Peterson, 2000; Thibaut \& Kelley, 1959) holds that ties exist because the parties involved perceive the benefits to outweigh the costs of that relationship. With competition, the expected cost of losing a prospective deal becomes real. And so becomes the cost of a partner who might have been suitable in the past but not so now. As I will show later, the characteristics of deals are such that it is indeed likely that a previous partner may not be the best one today.

Finally, studies of the social structure of competition (e.g.: Burt, 1993; Larson, 1992) look at transactions that rely not on prices and explicit contracts but on trust and ties. Burt's focus is on "a description of the way in which social structure renders competition imperfect." His "social structure" is the fabric with which we observe that "players trust certain others, are obligated to support certain others, are dependent on exchange with certain others, and so on." In effect, his thesis supports the hypothesis here, which is the contrapositive: competition renders social structures imperfect.

To summarize, theories from both economics and sociology appear either consistent with or is silent on the hypothesis (e.g., the point that competitive intensity delineates 
where the embeddedness argument might be less relevant). Empirically, however, there is less to say. Some researchers have studied settings of family-owned firms, where ties appear quite important. Examples include the apparel industry in New York ethnic communities (Uzzi, 1997) and the buffalo mozzarella cheese industry in the Caserta region of southern Italy (Locke, 2001). Where the setting resembles modern manufacturing or professional settings, such as Japanese supplier-manufacturer relationships (Dore, 1983) or bank lending (Uzzi \& Lancaster, 2003) the ties examined are vertical ones. ${ }^{3}$ Therefore, it is hard to draw comparable conclusions. Indeed, the points of departure for these theories often have only "social structural antecedents" (see Figure 3 in $(\mathrm{Uzzi}, 1997))$ and is silent on the impact of competition. But there are

two exceptions. First, Stuart (1998) shows that crowding enhances the propensity to ally. Although he does not explicitly states so, he suggests that crowded spaces are less competitive (pg. 673) and alliances are based on ties. Thus, his conclusion is consistent with my hypothesis. The other study (Podolny, 1994) shows that uncertainty enhances the importance of ties. Yet, uncertainty and competition can be orthogonal, and this is especially so in the VC setting: competition is about how many syndicates contend to invest in the same deal, and uncertainty is about what the deal might offer in financial return. Therefore, uncertainty plays the role of a control variable in my theory of competition and ties.

\section{Inside the Black Box}

A good theory should tease out the mechanisms underneath the high level connection between competition and ties. To uncover these mechanisms, I rely on personal

${ }^{3}$ Some settings also look at relationships between competitors (Ingram \& Roberts, 2000), analogous to inter-syndicate relationships. While interesting in their own right, these relationships are also not the subject of this paper. 
experience and the interviews. Two mechanisms emerge: competition can influence ties via pressures external (the portfolio company, industry jargon for the firm receiving the prospective investment) and internal (the VC firm). I defer the empirical testing of these to future research ${ }^{4}$, but it can nevertheless be helpful to elucidate the plausibility of these mechanisms here.

The first mechanism arises because greater competition means it is more unmistakable that the "customer (portfolio company) comes first." This is the familiar situation when "money is chasing deals" (Gompers \& Lerner, 2000). This in turn prods the lead VC to pitch a "dream team" syndicate with the right capabilities, lest it loses the deal to competing syndicates. Why don't the lead $\mathrm{VC}^{\prime}$ s previous syndicates have the right capabilities now? First, investments are different round-to-round. This is evident in the enormous within-VC maximum-minimum range in the amount invested (\$1.5 million; mean is $\$ 770,000)$, post-round valuation ( $\$ 11.2$ million; mean is $\$ 12$ million), and round date (3.9 years). This is despite specialization in the VC industry - e.g.: by industry or stage of start-up development.

Even if the current investment is similar to past ones, past ties are not always cheery in the VC industry, so competition can jolt a lead VC into selecting a new partner. Just how likely are past ties associated with bad deals? VC deals have notoriously fat-tail return distributions. The median return of VC funds is only $66 \%$ of the S\&P index for the 1980-01 period (Kaplan \& Schoar, forthcoming) and a nationwide dataset I got from Thomson Research shows that the standard deviation is 6.3 times the mean. It is

\footnotetext{
${ }^{4}$ I have, however, completed some preliminary estimation of the effects discussed here. Specifically, I estimate the partial effects of some of the "external" channels (the weight given to the portfolio company's view when money is chasing deals, need to pitch a "dream team", urgency in putting together the syndicate, asymmetry of information between VCs and portfolio company) and "internal" channels (capacity for and degree of internal scrutiny of deals, internal culture for collaboration versus competing among partners). The initial results (unreported here) appear to support the mechanisms described here.
} 
testimony to the power of embeddedness that lead VCs rely on past ties at all. ${ }^{5}$

The second mechanism is via pressure of an internal sort. Most decisions for a deal are made by the executive assigned to investigate it. The executive, should she decides to invest, then seeks approval from the VC firm's investment committee. With competition, the profile of the deal is raised in the eyes of other executives in the VC firm, who might offer alternative views on how to select a candidate VC. They might also scrutinize the selection more. The executive-in-charge would think twice about selecting a candidate VC based on her own ties. However, this still does not make past ties less important if the other executives help by putting forward candidate VCs of their own, on the basis of their past ties. The interviews suggest that this last possibility is remote, given the usual demands on the other executives and their awareness that helping this way can be interpreted as interfering. Instead, what is more likely is that the executive-in-charge pays more attention to $\mathrm{VC}$ selection, to demonstrate that she has done her work. A typical comment by executives is the following: "Even if my partners don't think I practice favoritism when I choose to work with guys [VC firms] from previous syndicates, I think the onus is on me to justify my selection. This onus is clearly heavier if the deal in question is a really hot one, in which everyone is looking at me and who I pick for the syndicate." (my clarification in square brackets) This is broadly consistent with theories on self-presentation and expectancy (e.g.: Goffman, 1959).

${ }^{5}$ Why don't portfolio companies see that the lack of the right complement of capabilities can be compensated by better coordination of VCs who have worked together in the past? For example, syndicates based on past ties might be higher-performing groups in terms of Hackman's criteria: effort expensed, knowledge brought to bear, and appropriate strategies (Hackman, 1987). Although theoretically plausible, such is not the sentiment from first-hand experience and the interviews. Portfolio companies do not value investing VCs acting in concert. On the contrary, they fear coordination against their interest at the board level. This is consistent with research on boards at VC-backed firms: portfolio companies prefer split or independent boards (Baker \& Gompers, 2003). 


\section{DATA, VARIABLES, ESTIMATION STRATEGY}

I use econometric tests with a large-scale sample to test my hypothesis. The dataset has over 200,000 observations, each of which codes whether a lead VC chooses a particular candidate VC, for 572 biotechnology VC rounds of investments in Massachusetts, from 1967 through 2004. To construct the dataset, I start with all 4,566 rounds from the National Venture Capital Association database. The data has investments by fund rather than VC firm. After aggregating to the firm level, I have 1,519 rounds.

From these, I made two culls of the dataset (details in Figure 1). First, I drop observations where I cannot identify the lead VC. To identify the lead VC, I supplement the data from VentureExpert, which has detailed information such as how much each VC invests in each round. I define the lead VC as that who invests the largest amount in the round. This definition is robust to sample selection bias, even in complex cases. For example, a smaller VC might have first discovered a portfolio company, and enlist the help of a bigger VC. It is the bigger VC that makes the decision on who to invite into the syndicate. The smaller $\mathrm{VC}^{\prime}$ s decision is similar to that of an invited VC, limited to whether to participate in the syndicate or not. If two VCs invest the same amount, I consider that ambiguous and drop the observation.

The second culling is to remove all follow-on rounds. These are investments subsequent to a previous round in the same portfolio company that involve the same lead and candidate VCs. Such rounds do not represent real choices that lead VCs have for candidate VCs, because practically all investment contracts give VCs a first right of refusal to invest in follow-on rounds.

Despite these culls, I am worried about their effects. So I look at what their impact might be. First, consider observations dropped because of lack of information. As Figure 1 shows, there is no significant difference between what is dropped and what is 
kept (comparing the left panel (a) with the right panel (c)). Importantly, the dropped rounds are more like the irrelevant follow-on rounds (panel (b)): they are of later stage, with higher round numbers, valuation, and round amounts. I am concerned, however, that they have smaller syndicate sizes because that is related to the dependant variable. Fortunately, syndicate size and round amounts are used in a Heckman correction for sample bias described later, partly alleviating this concern. Second, consider observations dropped because I could not identify who is the lead VC, because the VCs invested the same amounts. In regressions not reported here, I incorporate these dropped observations by assigning as lead VC the one with more board seats, or at random if board seat information is also non-discriminating. These regressions give the same qualitative results, with p-values maintained at the same cutoffs (e.g., $10 \%, 5 \%$, or $1 \%$. Third, consider those observations dropped because they are follow-on rounds. When I use a different technique to deal with follow-on rounds, with indicator dummies, I obtain the same qualitative results (unreported here).

\section{Dependent Variable and Overall Estimation Strategy}

The dependant variable, called TieNow, is 1 if the lead VC chooses the candidate VC for the deal and 0 otherwise. Consider Acceleron Pharma, a portfolio company based in Cambridge, MA, and founded in 2003 (Figure 2). It develops drugs to treat musculoskeletal and metabolic disorders. The lead VC in round 1 is Polaris. I create five observations, for Polaris-Avalon, Polaris-Venrock, Polaris-ATV, Polaris-Flagship, and Polaris-Sutter Hill. These observations have TieNow set to 1. I then build observations for all other VCs in the dataset that Polaris has not chosen for this syndication. These have TieNow equal to 0 .

I am concerned about incidental truncation. A lead VC could have selected a candidate $\mathrm{VC}$, but not done so because the deal is not big enough and is therefore not even a 
syndicate. To correct for this, I split the dataset into syndicates and non-syndicates. The former is used for estimating the main effects and the latter for sample correction. In this latter dataset, the CandidateVC field is empty and TieNow is set to 1. Using the Heckman procedure with unbalanced panel estimation clustered on lead VCs and with year dummies, my structural equation is:

$$
\text { TieNow }=\mathbf{X} \cdot \boldsymbol{\beta}+\varepsilon
$$

where $\mathbf{X}$ is the vector of explanatory variables. My selection equation is:

$$
\text { Selected }=\mathbf{X} \cdot \boldsymbol{\beta}+\psi \cdot \text { RoundAmount }+\xi
$$

where Selected is a binary for whether an observation is a syndicate, and RoundAmount is the amount invested in the round ${ }^{6}$. The intuition is that large rounds tend to be syndicates. The log-likelihood ratio for equation (2) is better than -359 in all estimations I use. I then calculate the inverse Mills ratio, and plug that for estimating equation (1) in the second stage.

The Stata Heckman command allows for only the standard probit-plus-OLS estimation, rather than the probit-plus-probit that I need, so I execute the stages "by hand" separately. This has the advantage of my running each stage with explicit first differencing and Huber-White corrections for heteroskedascity. The differencing also takes care of potential serial correlation in the idiosyncratic errors. Specifically, the estimations are consistent and unbiased as long as the idiosyncratic error at time $t$ is uncorrelated with the explanatory variables at other times for the same lead-candidate pair. Since observations at different times are for different portfolio companies, this

\footnotetext{
${ }^{6}$ Strictly speaking, the $\mathbf{X}$ in equation (2) excludes those variables in (1) that are highly correlated with selection, such as syndicate size (all selected observations have size greater than 1 and all unselected exactly 1) and past ties (all unselected have no ties).
} 
form of strict exogeneity assumption seems reasonable.

There is another kind of truncation: if syndicates bid for deals but do not succeed, selection is also unobserved. However, I consider these inefficient (i.e., failed) outcomes irrelevant because they fall outside the boundary of my hypothesis.

\section{Explanatory Variables}

The two main explanatory variables are the strength of past ties (TiePast) and the degree of competition (Competition). TiePast is measured with a count of previous syndicates in which the lead and candidate VCs have played the same roles. I count only ties from investments in Massachusetts biotech, since ties established differently, such as Silicon Valley semiconductors, are likely to be between different executives in the VC firms. In a variation of this measure, I include only previous "good" syndicates, defined as those in which the portfolio companies not end in bankruptcy or become defunct. I also depreciate the counts using annual rates of 0.1 and 0.5 - i.e., for the 0.1 rate, a tie last year would be counted not as 1 but as $1 / 1.1$, which is 0.91 .

Competition is unobservable directly. Even a direct count of the number of term sheets (industry jargon for offers to invest) a prospective portfolio company receives is insufficient. Negotiations underway that do not result in term sheets can intensify competition. The literature on "contestable markets" is about this sort of competition.

Traditional measures of competitive intensity include those such as number of firms in the industry, market share, concentration indices such as the Herfindahl index (Tirole, 1988). In the sociological literature, the standard measures include crowding and niche overlap (e.g.: Hannan \& Carroll, 1992; Podolny, Stuart, \& Hannan, 1996), and some also use concentration indices (e.g.: Podolny, 1993). Because the equivalent of these measures (.e.g:, share of VC deals, niche overlaps based on VCs' investment charters) would be very noisy for my purpose and do not capture unobserved competition, my 
empirical strategy is to employ instrumental variables (IVs) with two-stage-leastsquares (2SLS). In addition, for robustness, I do use these traditional measures, to create a set of variables for over-identifying tests (details later).

To create the IV, I first construct a proxy for competition by manually counting Factiva news articles. Why is this a good IV? This is because news about young companies is usually positive. Small young companies are news worthy if they perform well, while large old companies are news worthy if they perform badly despite their size and history. Positive news may invite competition, or perhaps the quality of the company leads to both news and competition. Either way, news about a focal portfolio company is correlated with competition for that company. ${ }^{7}$

What types of news should be counted? I count those that VC firms would get if they were to conduct a media search when conducting due diligence. Apart from regular media reports, I include PR (public relations) newswires, but exclude republished news and reports on pricing and market data.

The count is for 3- and 12-month periods prior to the round date. This rules out endogeneity due to reverse causality. Furthermore, unlike public market information such as impending IPOs or alliances, private equity deals rarely suffer news leakage, so it is unlikely that ties form before the news is out. I am also concerned about endogeneity arising from the count's correlation with the disturbance term. Therefore, I construct two more IVs that are correlated with news (and competition), but are otherwise exogenous. I will give the intuition for these two conditions of correlation

\footnotetext{
${ }_{7}^{7}$ Perhaps only tangentially related to this mechanism between news and competition, I have first-hand experience with the both variables, being a former executive and co-founder of a portfolio company, with over 748 article counts on the firm (URL to be provided on request; suppressed in this version of the paper to mask identity of author for refereeing purpose).
} 
and exogeneity ${ }^{8}$, and give formal evidence using a chi square-test and an overidentifying restriction test, respectively.

The first IV is the ratio of the VC industry's demand for deals to the supply of deals, at the time of the round date. As a measure at the industry level, this ratio is unlikely to be related to mechanisms such as agency effects at the portfolio company level. Yet, it is very believable that competition at the industry and company levels are related. The demand for deals is measured by summing the sizes of all biotech MA funds formed in a year. These amounts are drawn down, not committed, levels. Because funds take a couple of years after formation to enlist investors and another couple of years to invest, I lag the demand by three years. I also create an alternative measure by lagging just one year. The supply of deals is measured by the amount invested in all biotech MA firms in a year. ${ }^{9}$ Figure 2 shows the ratio over the years, confirming the intuition that the turn of the 1990's and 2000's are years of greater competition for investing into biotech deals.

The second IV is also a ratio of demand to supply, but for the city of the portfolio company. I measure demand for deals with the number of VC firms and supply with the number of portfolio companies, by city. For example, Boston has 73 VCs and 43 portfolio companies, so it has a ratio of $73 / 43$, or 1.69 , while Cambridge, with 11 VCs and 98 portfolio companies, has a ratio of $11 / 98$, or 0.11 . Naturally, there is spillover of demand across cities, but the IV approach does not need a variable of perfect correlation.

\footnotetext{
${ }^{8}$ Strictly speaking, the IVs should also satisfy rank and order conditions, but these are easily satisfied given the variation in the data, and they are automatically taken care of by the Stata computation machinery that I use.

${ }^{9}$ To clarify, this industry competitiveness ratio is correlated with the year dummies that I use in the estimation model. That, of course, does not affect the validity of the estimation, since it is the exogeneity with the disturbance term that impacts the properties of the estimators.
} 
To confirm the correlation condition for my IVs, I construct the reduced form equation:

$$
\text { News }=\gamma_{0}+\gamma_{1} \cdot \text { RatioByYear }+\gamma_{2} \cdot \text { RatioByCity }+ \text { Z. } \boldsymbol{\gamma}+\eta \text {. }
$$

where RatioByYear and RatioByCity are the two IVs, and $Z$ is a vector of control variables discussed in the next section. The equation is estimated using fixed-effects and robust standard errors. If significant correlation exists, I expect that a restricted model with null $\gamma_{1}=0$ and $\gamma_{2}=0$ to be rejected. The resulting chi-square statistic is 12378.10 for the basic model in which RatioByYear uses an unlagged numerator. It is 27246.89 for the numerator with one-year lag and 13296.63 for three-year lags. The $p$-values are all .000.

To show exogeneity, I employ an over-identifying restriction test. This requires me to run the main structural equation in the second stage (an expansion of equation (1) above):

$$
\text { TieNow }=\beta_{0}+\beta_{1} \text {. TiePast }+\beta_{2} \text {.Competition }+\beta_{3} \text {.TiePast } \times \text { Competition }+ \text { Z. } \boldsymbol{\beta}+\varepsilon\left(1^{\prime}\right)
$$

where TieNow is the dependant variable, TiePast the measure of past ties mentioned above, Competition the instrumented measure for competition, and $X$, as before, is the vector of control variables. I then regress $\varepsilon$ from equation $\left(1^{\prime}\right)$ on all the exogenous variables in equation (3) and test the over-identifying restriction. This yields a Wald statistic of .01467 , with a $p$-value of .9927 , happily passing the test. An F-test on the two IVs gives a $p$-value of .999 .

Why not add more IVs to improve the asymptotic efficiency of 2SLS? For example, another IV might be a different ratio of demand for and supply of deals. Demand can be measured with the number of funds started on the round date, and supply with the number of rounds by all portfolio companies on that date. Yet another IV is the postround valuation normalized say, by age or sales of the portfolio company at round date. I repeat first-stage regressions with different combinations of these IVs, and obtain the 
same qualitative (unreported) results. However, more IVs can increase the risk of biases, even for samples as large as half a million observations (1994), so I use just the earlier two IVs (Bound, Jaeger, \& Baker, 1995).

Indeed, why use IVs at all, since OLS estimation is more efficient than 2SLS? But OLS is biased if the proxy of news count is endogenous, so I check for that. I first obtain the combined residuals of a cross-section panel regression of news count on the IVs, and then add these residuals to the structural equation $\left(1^{\prime}\right)$ for the Heckman. The coefficient on the results has a $p$-value of .026 , confirming the endogeneity of news count, and therefore the need for the IV approach.

Finally, the regular Stata command does not have an IV version for probit estimation. In executing the estimation "manually," I have to correct for the standard errors: if the probit asymptotic variance is $\Omega$, the reduced form variables $Z$, and the instrumental variables $\mathrm{X}$, then the corrected asymptotic covariance matrix is:

$$
\left(X^{\prime} Z\right)^{-1} X^{\prime} \Omega X\left(Z^{\prime} X\right)^{-1} .
$$

Because these matrices have at least one dimension of the order of over 200,000, I do not have sufficient computational resources to execute the correction. To estimate the correction factor, I compare the $p$-values using an OLS 2SLS versus manually executing the two stages using OLS for the variable of interest, TiePast $\times$ Competition. The former is .086 and the latter .078 , a $10 \%$ difference. In the estimation results below, I shall bear this in mind.

\section{Control Variables}

I control for the year of the round, which picks up an assortment of variations. For example, in the year of a round, a candidate VC might be under pressure to invest, or conversely, have run out of funds to invest. The news count may also correlate with 
time, such as when the media is eager to write about start-ups during a boom.

Another control is differences in status. Podolny (1994) shows that in investment banking syndicates, the more similar in status are lead and candidate banks, the higher chance that the lead will select the candidate. This is because status signals quality and ties with a candidate of higher status inflates the lead bank's status. In our context, a different dynamic is also in play. Status homophily often means similarity in investment amounts, and in turn similarity in the amount of control that can be exercised say, at the board. Therefore, homophily makes it difficult for the lead VC to make decisions after investment, an issue that does not arise in one-time investment banking syndications. Regardless of whether the quality or control effect is more dominant, the status gap between the lead and candidate VCs needs to be controlled for. To measure status, I use the Bonacich measure for firm $i$ in relation to other firms $j$ as:

$$
C_{i}=\sum\left[A_{i j} \cdot\left(\alpha+\beta . C_{j}\right)\right]
$$

where $A_{i j}$ is the adjacency matrix of network ties, $\alpha$ is a normalization parameter selected so that the sum of squares of the $C_{i}^{\prime}$ s is the size of the network of ties, and $\beta$ is an attenuation factor that sets the degree of dependency of each firm's measure on the measures of the adjacent firms in the network of ties. For robustness, I also measure status using four other indices of centrality: degree, closeness, betweenness, and eigenvetors. Figure 4 shows the details, including the correlations.

Following Podolny (1994), I use an spline specification to control for status. Two dummies are used for the lead VC's status, one for the case if its status is higher than the candidate $\mathrm{VC}^{\prime} \mathrm{s}$, and other if it is lower. Two are likewise used for the candidate 
VC's status. ${ }^{10}$

I also control for the degree of uncertainty. Podolny (1994) shows that the degree of uncertainty positively moderates the effect of past ties and the status gap between lead and candidate VCs. I measure uncertainty by the age of the firm at round date. I note that uncertainty is orthogonal to the quality of the firm - distressed firms can have certainty, even if the certainty is towards bankruptcy.

Finally, I control for syndicate size, since the larger the syndicate, the likelier that a lead VC has room for another candidate VC. This impacts TieNow, the dependant variable.

For robustness, I construct even those controls that seem less compelling. I expect that these do not alter the results nor add to explanatory power. One is the investment amount. Another is the potential for agency, using several measures that depend on specificity of investments and growth opportunities: intangible assets as a proportion of total assets, R\&D expenses over sales, market-to-book ratio (Gompers, 1995). This information is from CompuStat ${ }^{11}$. A third one is the size of the lead VC, measured with the number of portfolio companies and the amount of funds under management. A fourth is the portfolio company's industry. Finally, there is the age of the portfolio company at round date.

\footnotetext{
${ }^{10}$ That paper uses the complicated spline specification rather than the simpler measure of the status gap with "lead status minus candidate status" because positive values are desired, for easier interpretation. I follow that preference for comparison here.

11 ComputStat has information only for listed companies. For unlisted ones, I follow Gomper's methodology by estimating them using ratios for listed firms with the same four-digit SIC and in the same year. Because Venture Economics (VE) uses a proprietary industry classification, I first have to construct a concordance between the VE and SIC (CompuStat) classifications, using matched listed firms from both. This is complicated by CompuStat's assigning multiple codes to some firms. So I first try to match on the primary code, then the secondary, etc.
} 


\section{SUMMARY STATISTICS AND ESTIMATION RESULTS}

Figure 5 shows the summary statistics. The left panel shows the main dataset for estimation. These are observations for syndicate rounds, where a lead VC's choice of a candidate VC is observed. The right panel is for non-syndicate rounds, in which the "lead VC" is alone, so her choice is unobserved. This panel is used for sample correction.

Two points are interesting. First, the heterogeneity in the dataset suggests external validity. For example, the mean and standard deviation of the investment amount is $\$ 6.7$ million and $\$ 15.2$ million, respectively, compared with the nation's $\$ 12.1$ million and $\$ 49.2$ million, which I got from Venture Economics.

Second, just eyeballing the two panels, it appears that they have different characteristics. For example, News12MthsBefore, the proxy for Competition, has a mean that is one-third larger than that in the right panel. Therefore, I expect a significant inverse Mill's ratio in sample correction.

In Figure 6, Model (1) shows the baseline empirical result. For easier interpretation, I center the key explanatory variables: TiePast, Competition (instrumented), and Uncertainty, which interacts with these. All are panel estimations corrected using Huber-White robust standard errors.

The key variable of interest is "TiePast $\times$ Competition (instrumented)," shown in bold. As predicted, its coefficient is negative and statistically significant. In this case, TiePast is the count of all syndicates (including those whose portfolio companies result in bankruptcies and distress, which I exclude in the next model) depreciated at 0.5 per year. At one standard deviation for Competition (21.74), the partial for TiePast changes from 3.23 for the mean observation to:

d TieNow/d TiePast $=3.23-.229 \times 21.74=-1.76$, 
reversing the positive impact of TiePast on TieNow. The $p$-value for this term is .006 , so even though standard errors are unadjusted properly for 2SLS, a 10\% inflation on this (as described earlier) still keeps the significance.

The other coefficients are all either of the predicted sign or are insignificant. As discussed earlier, Competition by itself has several effects, and the estimation gives a mildly positive, but statistically insignificant, effect. Although also statistically insignificant, Uncertainty has a positive sign, consistent with Podolny (1994). The interaction TiePast $\times$ Uncertainty is predicted to be positive, and it is so. Although statistically insignificant, the interaction of the Bonacich terms with Uncertainty is negative with status homophily (lead's status lower than candidate's, so an increase in the former closes the status gap) and positive otherwise. This suggests that the need for power (hence different status) dominates the signal for quality (same status). SyndicateSize has the predicted positive effect on ties. Finally, the Mill's ratio has a significant coefficient, confirming our earlier intuition.

For robustness, I re-do the estimations with alternative measures. The conclusion is unchanged:

- Model 2 uses an extended and different set of IVs. Instead of News3MthsBefore, I use News12MthsBefore. Instead of lagging the numerator of RatioByYear (ratio of VC industry's demand to supply) by 3 years, I lag it by 1 year. I also add the two other IVs described earlier: a ratio of demand (measured with the number of funds started on the round date) to supply (number of rounds by all portfolio companies on that date) and post-round valuation over sales. The statistical significance on the interaction of TiePast and Competition is lost, but a standard deviation increase in Competition (which is 38.90) still reduces the partial on ties from 2.01 to:

$$
2.01-.014 \times 38.90=1.47 \text {. }
$$


This set of IVs passes the overidentifying test too, although as explained, I run a higher risk of bias.

- Model 3 uses an alternative measure of TiePast. I exclude counting past syndicates that result in bankruptcy or distress, and depreciate at a 0.1 rather than 0.5 annual rate. The interaction of TiePast and Competition is statistically significant, and a standard deviation increase in Competition reduces the partial on ties from .439 to:

$$
.439-.083 \times 21.74 \text { (S.D. })=-1.37 \text {. }
$$

- Model 4 uses an extended set of control variables described earlier. As expected, the standard errors increase, so much that the interaction between TiePast and Competition is not statistically significant. However, a reduction in the effect of TiePast continues to be seen.

\section{ALTERNATIVE INTERPRETATIONS AND DISCUSSION}

Could the evidence be explained by a different mechanism? For example, News could pick up more than Competition. Even without competition, news can increase the intensity of internal scrutiny, and prod the executive in the VC firm into enlarging the search set of candidate VCs. Unrelated to competition, news can also reduce information asymmetry. Portfolio companies have more information on themselves than investing VCs can ever hope to have. Therefore, working with another VC (i.e., syndicate) and especially with a VC from a previous syndicate (i.e., past ties) helps by keeping more trusted pairs of eyes on a portfolio company. These alternative channels may well exist, but the use of instrumental variables, which are unlikely to be correlated with them, have addressed them.

I also leave for further research three interesting areas for development. First, an area to clarify is the mechanisms with which competition affects ties: the pressure from 
external and internal sources. A common way to identify mediating effects is to create a statistic (Sobel, 1982) ${ }^{12}$. Preliminary regressions not reported here suggest these mechanisms are at work.

Second, there is an issue of what a tie is. For example, Burt argues that "the value of a relationship is not defined inside the relationship; it is defined by the social context around the relationship." (Burt, 2002) In my setting, this means that the strength of past ties may be more than a simple count of involvement in previous syndicates. For example, it could be a measure of the structural equivalence of the current situation and past situations: are the lead and candidate VCs related to the same lawyers, auditors, bankers for the portfolio company, same lawyers, auditors, bankers for the VCs, and same third-party syndicate partners?

Finally, there are two settings in which competition seems to be associated with strong ties. First, in the literature on relationship banking, there is evidence that strong rather than arms-length relationships between banks and their borrowers can better withstand competition among banks for borrowers (Boot \& Thakor, 2000). Is this co-existence of ties and competition inconsistent with my hypothesis? I do not think so, because the tie between bank and customer is an example of vertical ties, rather than the horizontal type of concern in this paper. Second, much has been written about Silicon Valley's intense competition and strong ties (e.g.: Bresnahan, Gambardella, \& Saxenian, 2001). Again, this co-existence of ties and competition appears inconsistent with my hypothesis. It is unclear, however, whether the ties and competition are about the same units as described in this paper. For example, ties depicted are often of those among

\footnotetext{
${ }^{12}$ Denote $\mathbf{Y}$ as the dependent variable, $\mathbf{X}$ explanatory, and $\mathbf{M}$ mediating. Construct the model as $\mathbf{Y}=\mathbf{X} \beta+\varepsilon$, $\mathbf{M}=\mathbf{X} \boldsymbol{\delta}+\boldsymbol{\eta}$, and $\mathbf{Y}=\mathbf{X} \boldsymbol{\alpha}+\mathbf{M} \boldsymbol{\gamma}+\boldsymbol{\zeta}$. The significance of the mediating effect has a $\mathbf{Z}$ distribution and the statistic is $\delta^{\prime} \gamma\left[\delta^{\prime} \delta . \operatorname{SE}(\gamma)^{2}+\gamma^{\prime} \gamma \cdot \operatorname{SE}(\delta)^{2}\right]^{-1}$ where $\operatorname{SE}($.$) is the standard error.$
} 
employees (Almeida \& Kogut, 1999), while competition portrayed is often those among start-ups. Therefore, the conclusions appear not comparable. It is worthwhile clarifying this in future research.

\section{CONCLUSIONS AND PRACTICAL IMPLICATIONS}

This paper indirectly confirms the theory that past ties is a good predictor of current ties, but extends the theory by showing that the prediction is conditional on the degree of competitiveness. An intriguing implication is that competition offers one explanation around the conundrum of why, if past ties predict present ties, we should see any new ties at all. It also explains the origin of weak ties or structural holes, of why VCs connected well with one cluster might somehow also have connections with another.

Practically, the finding could be an important piece of the puzzle of how VCs fund entrepreneurs in the latter's quest for growth. It raises issues such as whether entrepreneurs should actively increase the level of real or perceived competition among VCs, and the implications of such competitive intensity on the structure of VC syndicates bidding for the deals. A natural follow-on question is what the VC syndicates that result from more competition might mean for the performance and growth of entrepreneurial firms. 


\section{APPENDIX}

Figure 1 - Comparison of dropped and kept observations.

\begin{tabular}{|c|c|c|c|c|c|c|c|c|c|}
\hline Round Date & 226 & 15JUL1997 & 5.6 & 868 & 10FEB1996 & 6.0 & 425 & 29DEC1993 & 7.2 \\
\hline Round Valuation & 226 & 8.4 & 29.3 & 868 & 6.4 & 10.5 & 425 & 5.0 & 12.6 \\
\hline Round Number & 226 & 2.8 & 2.4 & 868 & 4.6 & 2.8 & 425 & 1.5 & 1.4 \\
\hline Sales 3 yrs before & 6 & 494.7 & 372.4 & 49 & 309.6 & 343.5 & 14 & 363.1 & 360.2 \\
\hline Sales last yr & 22 & 338.3 & 284.9 & ||97 & 382.3 & 267.4 & 37 & 396.8 & 280.2 \\
\hline Assets 3 yrs before & 4 & 452.8 & 299.2 & 17 & 317.6 & 283.0 & 3 & 440.3 & 288.7 \\
\hline Assets last yr & 1 & 760.0 & . & 3 & 523.5 & 409.6 & 2 & 405.3 & 501.6 \\
\hline Founding Date & 197 & 20FEB1993 & 7.6 & 790 & 01JAN1991 & 7.2 & 352 & 18MAR1990 & 9.1 \\
\hline Round amount & 218 & 9872.3 & 30371.2 & 844 & 6772.8 & 11057.2 & 412 & 5664.8 & 13700.3 \\
\hline Syndicate size & 226 & 1.7 & 0.4 & 868 & 3.5 & 2.9 & 425 & 2.6 & 1.7 \\
\hline News 12 mths before & 22 & 6.5 & 10.0 & 867 & 23.9 & 55.5 & 425 & 11.1 & 38.1 \\
\hline News 3 mths before & 22 & 2.5 & 4.2 & 867 & 7.6 & 18.6 & 425 & 3.6 & 13.5 \\
\hline
\end{tabular}

* Dropped due to lack of information or when two VCs invest the same amount in a syndicate, so it is unclear from the data I have which is the lead VC. 
Figure 2 - Example Portfolio Company (Acceleron Pharma, Inc.)

\begin{tabular}{|c|c|c|c|c|}
\hline General Partner (GP) & Fund & Security Type & $\begin{array}{l}\text { Equity (\$ } \\
\text { 000s) }\end{array}$ & $\begin{array}{l}\text { Debt (\$ } \\
\text { 000s) }\end{array}$ \\
\hline Round 1 & $2 / 13 / 2004$ & Early Stage & & \\
\hline Avalon Ventures & Avalon Ventures VI & Series A Conv Pref Stock & 200 & 0 \\
\hline Venrock Associates & Venrock Associates IV, L.P. & Series A Conv Pref Stock & 1560 & 0 \\
\hline Advanced Tech Ventures (ATV) & Advanced Tech Ventures VII (ATV VII) & Series A Conv Pref Stock & 210.3(e) & 0 \\
\hline Advanced Tech Ventures (ATV) & ATV Entrepreneurs VI & Series A Conv Pref Stock & 210.3(e) & 0 \\
\hline Advanced Tech Ventures (ATV) & ATV Entrepreneurs VII & Series A Conv Pref Stock & 210.3(e) & 0 \\
\hline Polaris Venture Partners & Polaris Venture Partners IV, L.P. & Series A Conv Pref Stock & 2586 & 0 \\
\hline Advanced Tech Ventures (ATV) & Advanced Tech Ventures VI & Series A Conv Pref Stock & 210.3(e) & 0 \\
\hline Flagship Ventures & Applied Genomic Tech Capital Fund, L.P. & Series A Conv Pref Stock & 1914 & 0 \\
\hline Venrock Associates & Venrock Associates - Unspecified Fund & Series A Conv Pref Stock & 354 & 0 \\
\hline Sutter Hill Ventures & Sutter Hill Ventures & Series A Conv Pref Stock & 1500 & 0 \\
\hline Round 2 & $9 / 28 / 2004$ & Early Stage & & \\
\hline Venrock Associates & Venrock Associates IV, L.P. & Series A Conv Pref Stock & 2923 & 0 \\
\hline Advanced Tech Ventures (ATV) & ATV Entrepreneurs VI & Series A Conv Pref Stock & 132.3(e) & 0 \\
\hline Advanced Tech Ventures (ATV) & ATV Entrepreneurs VII & Series A Conv Pref Stock & 132.3(e) & 0 \\
\hline Advanced Tech Ventures (ATV) & Advanced Tech Ventures VI & Series A Conv Pref Stock & 3500 & 0 \\
\hline Advanced Tech Ventures (ATV) & Advanced Tech Ventures VII (ATV VII) & Series A Conv Pref Stock & 132.3(e) & 0 \\
\hline Polaris Venture Partners & Polaris Venture Partners IV, L.P. & Series A Conv Pref Stock & 4241 & 0 \\
\hline Venrock Associates & Venrock Associates - Unspecified Fund & Series A Conv Pref Stock & 668 & 0 \\
\hline Flagship Ventures & Applied Genomic Tech Capital Fund, L.P. & Series A Conv Pref Stock & 3592 & 0 \\
\hline Sutter Hill Ventures & Sutter Hill Ventures & Series A Conv Pref Stock & 979 & 0 \\
\hline
\end{tabular}


Figure 3 - Measuring competition for deals. One instrumental variable used is the industry ratio of demand (sum of fund sizes, with alternative years of lag) to supply (sum of investments into portfolio companies)

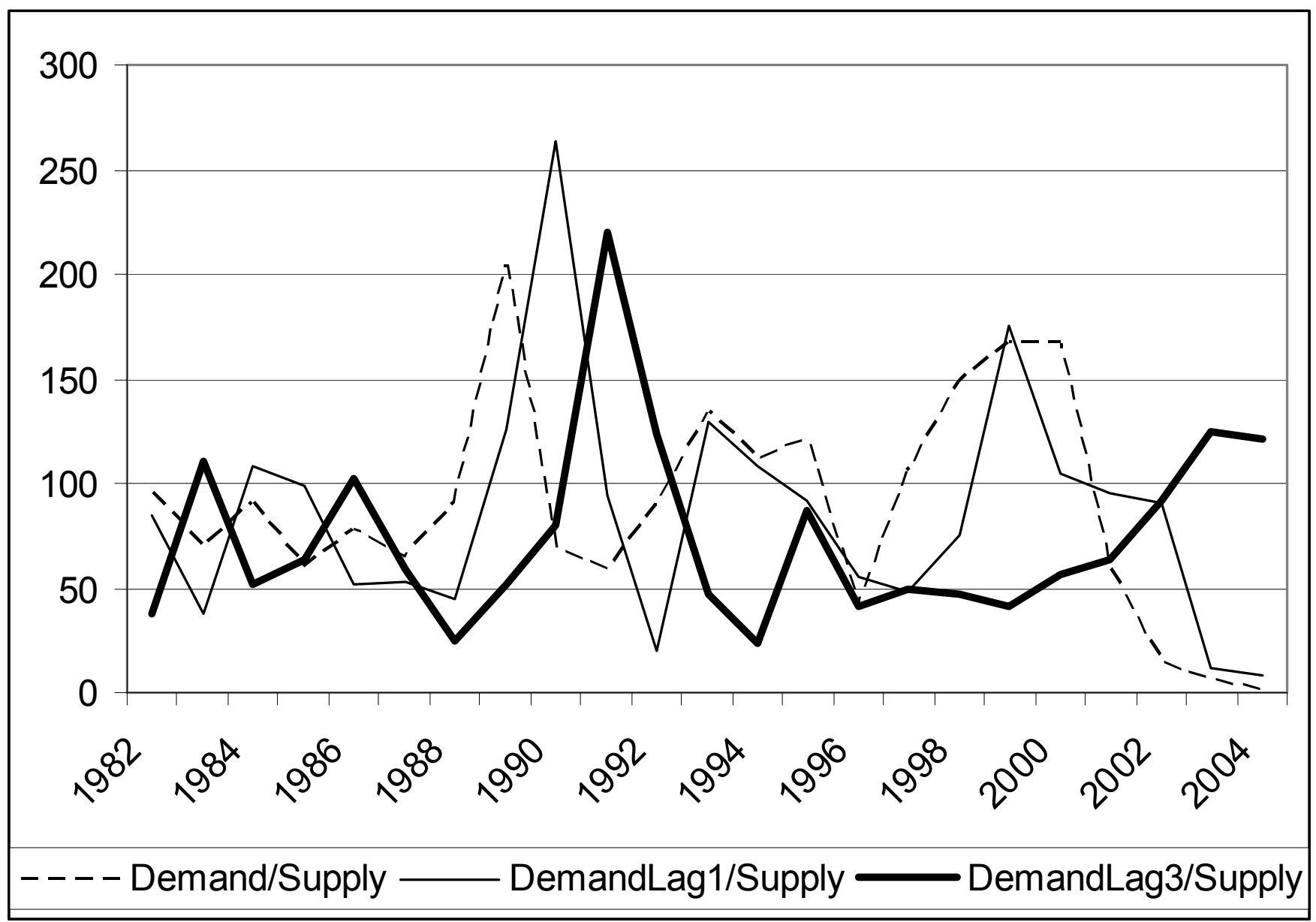


Figure 4-Measuring status (continued on next page).

$\begin{array}{lccccc} & \text { Bonacich } & \text { Degree } & \text { Closeness } & \text { Betweenness } & \text { Eigenvector } \\ \text { Mean } & 3.115 & 2.208 & 16.187 & 0.752 & 6.725 \\ \text { Std Dev } & 4.373 & 1.659 & 1.894 & 1.18 & 5.045 \\ \text { Sum } & 881.5 & 624.823 & 4580.945 & 212.816 & 1903.034 \\ \text { Variance } & 19.126 & 2.752 & 3.586 & 1.392 & 25.452 \\ \text { SSQ } & 8158.25 & 2158.342 & 75166.852 & 553.943 & 20000.002 \\ \text { MCSSQ } & 5412.518 & 778.825 & 1014.713 & 393.905 & 7203.047 \\ \text { Euc Norm } & 90.323 & 46.458 & 274.166 & 23.536 & 0 \\ \text { Minimum } & 0 & 0 & 0.353 & 0 & 30.514 \\ \text { Maximum } & 30 & 10.638 & 18.528 & 9.385 & \\ \text { Correlations } & & & & & \\ \text { Bonacich } & 1.0000 & & & & 1.0000 \\ \text { Degree } & 0.9247 & 1.0000 & & & \end{array}$

Top 10 VC firms on Bonacich Measure (see next page for ID)

\begin{tabular}{cclcc} 
ID & Bonacich & \multicolumn{1}{c}{ Firm } & Investments (\$'000) & Num of portfolio companies \\
\hline \hline 628 & 30 & Sands Brothers \& Co., Ltd. & 51,510 & 15 \\
635 & 27 & Schroders PLC & 209,618 & 128 \\
253 & 25 & Eiken Chemical, Ltd. & 5,000 & 1 \\
763 & 18 & Womens Growth Capital Fund & 26,792 & 18 \\
769 & 17 & Zero Stage Capital Co., Inc. & 337,952 & 105 \\
252 & 16 & Edwards Lifesciences & 11,426 & 4 \\
489 & 16 & Morgenthaler Ventures & $1,295,878$ & 216 \\
764 & 16 & Worms Capital Mgt (AKA: Permal Capital Mgt) & 11,695 & 4 \\
597 & 14 & RFE Investment Partners & 452,385 & 129 \\
638 & 14 & Seacoast Capital & 87,829 & 24
\end{tabular}


Figure 4 (continued) - Measuring status $(\mathrm{N}=283)$. The centrality measures are based on ties from previous syndications. VCs are depicted as nodes. An arrow from one VC to another means that the former has selected the latter in a previous syndicate. Isolated nodes on left are VCs who select no VCs before. All lead VCs are shown, but only candidate VCs who have been selected by some lead VC are shown.

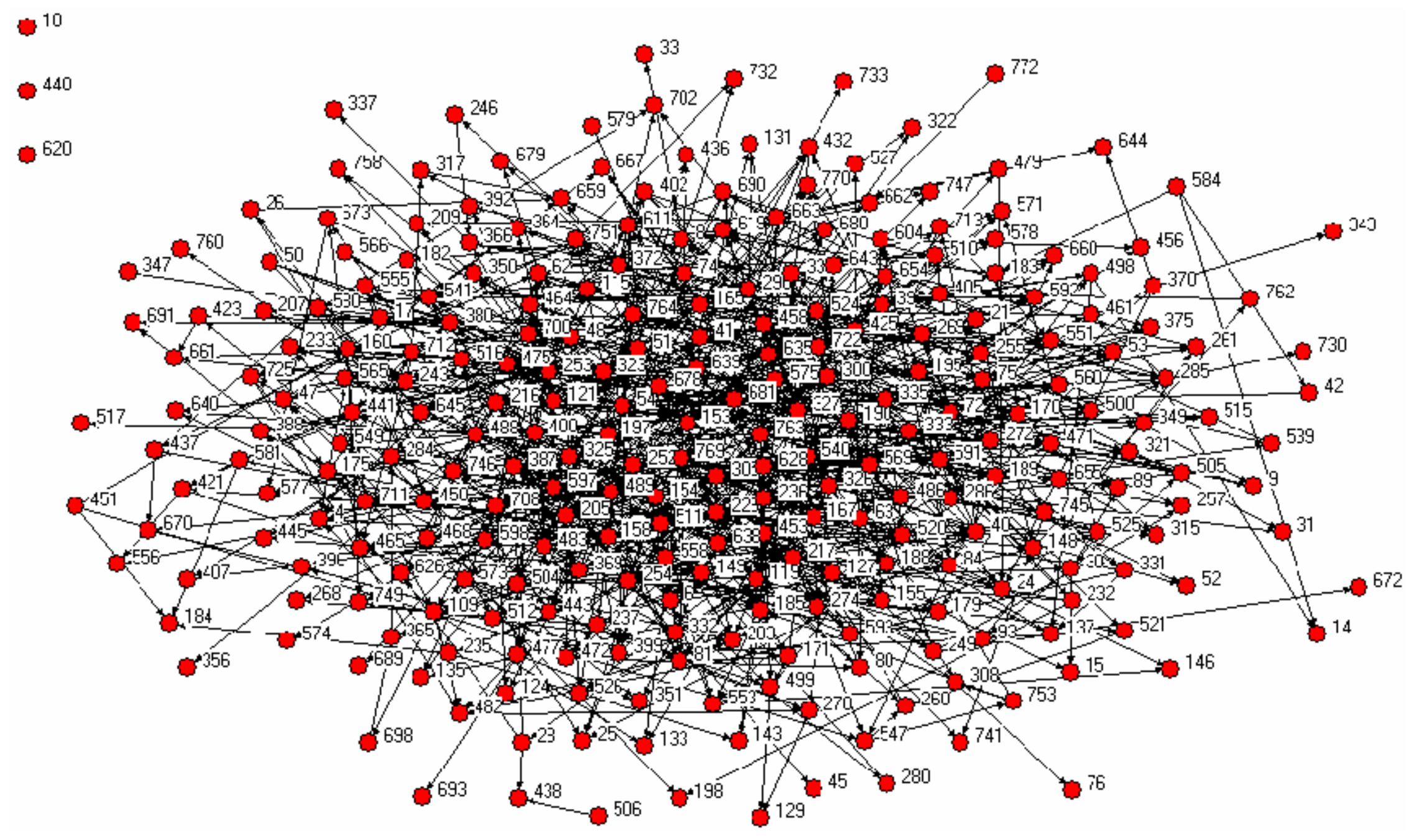


Figure 5 - Summary statistics ( $\mathrm{L}=$ lead VC, C = candidate VC, PC=portfolio company).

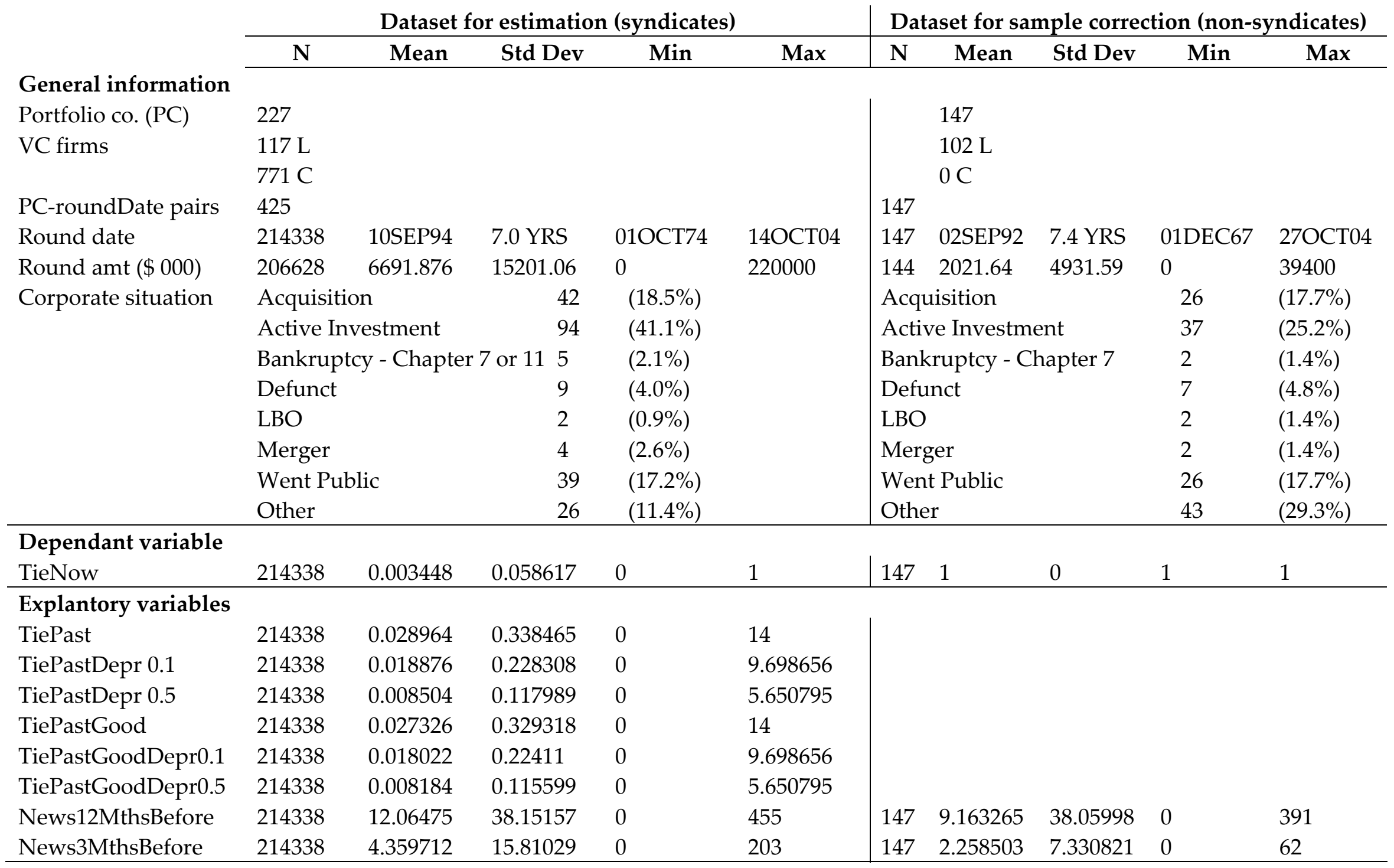

...continued 


\begin{tabular}{|c|c|c|c|c|c|c|c|c|c|c|}
\hline \multicolumn{11}{|l|}{ Control variables } \\
\hline \multicolumn{11}{|l|}{ investment } \\
\hline L's debt investment & 96375 & 0.28 & 3.117964 & 0 & 35 & 147 & 58.10204 & 660.8185 & 0 & 8000 \\
\hline Syndicate size & 214338 & 3.428058 & 1.552515 & 2 & 11 & 147 & 1 & 0 & 1 & 1 \\
\hline L's Bonacich & 214338 & 1.093525 & 1.551944 & 0 & 8 & 147 & 0.918367 & 1.230381 & 0 & 5 \\
\hline C's Bonacich & 214338 & 0.233463 & 0.82281 & 0 & 8 & 147 & 0 & 0 & 0 & 0 \\
\hline Age at round date & 191208 & 2.85802 & -3.47719 & 4.860274 & 24.4274 & 104 & 3.42205 & -8.13735 & $7.920548 \quad 5$ & 4.03836 \\
\hline Intangibles/assets & 175017 & 0.506267 & 2.394125 & $\begin{array}{ll}0 & 1\end{array}$ & 8.28083 & 122 & 0.243469 & 0.990668 & .00325221 & 0.13158 \\
\hline R\&D/assets & 171162 & 0.334087 & 0.645228 & 09 & 0.558194 & 120 & 0.28736 & 0.291595 & 01 & 0.713693 \\
\hline \multirow[t]{3}{*}{ Industry } & \multicolumn{2}{|c|}{ Biotech } & \multicolumn{2}{|c|}{$91 \quad(40.1 \%)$} & & \multicolumn{3}{|c|}{ Biotech } & & $\begin{array}{r}696 \\
(34.01 \%)\end{array}$ \\
\hline & \multicolumn{2}{|c|}{ Medical/health } & 130 & \multicolumn{2}{|l|}{$(57.3)$} & \multicolumn{3}{|c|}{ Medical/health } & 94 & $95 \%)$ \\
\hline & \multicolumn{2}{|c|}{ Unknown } & 6 & \multicolumn{2}{|l|}{$(2.6)$} & \multicolumn{3}{|c|}{ Unknown } & $(2$. & $(2.04 \%)$ \\
\hline
\end{tabular}

Note: TiePastGoodDepr0.5 is count of syndicates prior to round date, limiting only to those whose PC's have not ended in bankruptcy or distress, and depreciating at 0.5 per year. 
Figure 6 - Estimation results, using two-stage panel probits with Heckman correction. Figures in brackets are heteroskedascity-robust standard errors. ( $\mathrm{L}=$ lead $\mathrm{VC}, \mathrm{C}=$ candidate VC, PC=portfolio company; Cent=centered, =dropped because of collinearity)

Dependant variable: TieNow

(1)

(2)

(3)

(4)

Baseline $\quad$ Extended IVs Alternative EV Extended CV's

\begin{tabular}{|c|c|c|c|c|}
\hline TiePastDepr0.5 & $3.23(.93)^{* * *}$ & $2.01(1.14)^{*}$ & & $2.90(1.09)^{*}$ \\
\hline TiePastGoodDepr0.1 & & & $.439(.053)^{* * *}$ & \\
\hline Competition & $.053(.122)$ & $.006(.003)^{*}$ & $.058(.119)$ & $.154(.057)^{*}$ \\
\hline TiePastDepr0.5 $\times$ & $-.229(.084)^{* * *}$ & $-.014(.013)$ & & $-.015(.020)$ \\
\hline Competition & & & & \\
\hline $\begin{array}{l}\text { TiePastGoodDepr } 0.1 \times \\
\text { Competition }\end{array}$ & & & $-.083(.016)^{* * *}$ & \\
\hline Uncertainty & $211.75(189.44)$ & $282.01(84.52)^{* * *}$ & & $\begin{array}{l}535.63 \\
(100.83)^{* * *}\end{array}$ \\
\hline TiePastDepr0.5 $\times$ Uncertainty & $\begin{array}{l}1958.30 \\
(733.35)^{* * *}\end{array}$ & $1364.06(968.96)$ & & $\begin{array}{l}2100.92 \\
(972.06)^{* *}\end{array}$ \\
\hline
\end{tabular}

TiePastGoodDepr0.1 $\times$

24.903 (118.274)

Uncertainty

L's Bonacich if L lower than C

L's Bonacich if L higher than C. .015 (.134)

$\mathrm{C}^{\prime}$ s Bonacich if $\mathrm{C}$ lower than $\mathrm{L}$ -

$\mathrm{C}^{\prime}$ s Bonacich if $\mathrm{C}$ higher than Ll-

Interactions of above 4

Bonacich measures with

Uncertainty

$\left\{\begin{array}{l}-173.20(217.12) \\ 21.92(223.71) \\ -\end{array}\right.$

SyndicateSize

$.144(.023)^{* * *}$

1977

1981

$.567(.584)$

$.037(.102)$

1982

1983

1986

1987

1988

1989

1992

1993

1994

1995

1996

1997

$.032(.267)$

$-.178(.251)$

$-.122(.149)$

$.244(.123)^{* *}$

$-.279(.061)^{* * *}$

$-.244(.141)^{*}$

$-.163(.103)$

$-.047(.014)^{* * *} \quad .012(.132) \quad .143(.080)^{*}$

$.113(.085)$

$.047(.297)$

$.145(.087)^{*}$

$.050(.075)$

$.273(.168)$

$-.177(.101)^{*}$

$-283.38$

$(80.01)^{* * *}$

$-203.72(222.17) \quad-214.41$

$-84.20(22.77)^{* * *}$

$17.38(221.61)$

$(120.28)^{*}$

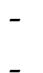

227.05 (194.04) -

$.120(.017)^{* * *}$

-

147.34 (99.33)

-.025 (.159)

$.142(.022)^{* * *}$

$.222(.033)^{* * *}$

$-$

$.589(.574)$

$.307(.167)^{*}$

$.048(.092)$

$-.063(.106)$

$-.064(.069)$

$-.287(.130)^{* *}$

$.059(.244)$

$-$

$-.214(.149)$

$-.173(.247)$

$-.421(.160)^{* * *}$

$.298(.137)^{* *}$

$-.116(.151)$

$-.645(.197)^{* * *}$

$-.013(.107)$

$.302(.133)^{* *}$

$-.742(.180)^{* * *}$

$-.040(.147)$

$.099(.088) \quad .043(.081)$

$-.137(.119)$

$.025(.298)$

$-.149(.150)$

$.035(.120)$

$.137(.091)$

$-.267(.149)^{*}$

$.007(.074)$

$.052(.076)$

$-.404(.149)^{* * *}$

$.185(.074)^{* *}$

$.283(.162)^{*}$

$-.147(.130)$

$-.321(.115)^{* * *} \quad-.215(.101)^{* *}$

$-.298(.164)^{*}$

$-.074(.108)$

$-.142(.068)^{* *} \quad-.066(.108)$

$-.583(.135)^{* * *}$ 


\begin{tabular}{|c|c|c|c|c|}
\hline 1998 & $.125(.069)^{*}$ & $.040(.086)$ & $.136(.074)^{*}$ & $-.298(.143)^{* *}$ \\
\hline 1999 & $-.038(.084)$ & $-.125(.064)^{* *}$ & $.003(.091)$ & $-.460(.146)^{* * *}$ \\
\hline 2000 & $.057(.090)$ & $-.093(.104)$ & $.056(.091)$ & $-.228(.116)^{* *}$ \\
\hline 2001 & .077 (.117) & $-.078(.099)$ & $.037(.132)$ & $-.339(.146)^{* *}$ \\
\hline 2002 & $-.028(.174)$ & $-.154(.084)^{*}$ & $-.030(.166)$ & $-.362(.103)^{* * *}$ \\
\hline 2003 & $-.222(.274)$ & $-.369(.090)^{* * *}$ & $-.291(.293)$ & - \\
\hline 2004 & $-.555(.307)^{*}$ & $-.377(.071)^{* * *}$ & $-.614(.263)^{* *}$ & - \\
\hline \multicolumn{5}{|c|}{ Years dropped due to collinearity: $78,79,80,84,85,90,91$} \\
\hline \multirow[t]{2}{*}{ Round amount } & & & & $-1.96 \mathrm{E}-6$ \\
\hline & & & & $(6.74 \mathrm{E}-6)$ \\
\hline Market-to-book & & & & $-.071(.028)^{* *}$ \\
\hline \multirow[t]{2}{*}{ L's total disbursed } & & & & $8.15 \mathrm{E}-7$ \\
\hline & & & & $(3.05 \mathrm{E}-7)$ \\
\hline Industry dummy & & & & $-.638(.263)^{* *}$ \\
\hline \multicolumn{5}{|l|}{ (Medical/health) } \\
\hline PC age at round date & & & & $.047(.026)^{*}$ \\
\hline \multirow[t]{2}{*}{ Inverse Mill's ratio } & 108.128 & 171.890 & $97.099(56.756)^{*}$ & $89.314(82.766)$ \\
\hline & $(46.825)^{* *}$ & $(91.980)^{*}$ & & \\
\hline \multirow[t]{2}{*}{ Constant } & -34.462 & -52.416 & -31.285 & $-29.622(23.726)$ \\
\hline & $(13.430)^{* *}$ & $(26.516)^{* *}$ & $(16.311)^{*}$ & \\
\hline $\mathrm{N}$ & 38964 & 38964 & 38964 & 29223 \\
\hline Pseudo $\mathrm{R}^{2}$ & .0571 & .0530 & .0587 & .0455 \\
\hline Log pseudo-LR & -695.7588 & -698.77258 & -694.54989 & -515.5557 \\
\hline \multicolumn{5}{|c|}{ Overidentifying test for IVs } \\
\hline Degree of freedom & 1 & 3 & 1 & 1 \\
\hline$X^{2}$ & .0121448 & .16516625 & .00397562 & .04393533 \\
\hline $\mathrm{p}$-value & .993946 & .98300648 & .94972468 & .83397398 \\
\hline
\end{tabular}




\section{REFERENCES}

Almeida, P., \& Kogut, B. 1999. Localization of knowledge and the mobility of engineers in regional networks. Management Science, 45: 905-917.

Arrow, K. J. 1974. The limits of organization (1st ed.). New York: Norton.

Baker, M., \& Gompers, P. A. 2003. The determinants of board structure at the initial public offering. Journal of Law \& Economics, 46(2): 569-598.

Baum, J. A. C., \& Oliver, C. 1992. Institutional embeddedness and the dynamics of organizational populations. American Sociological Review, 57(4): 540-559.

Blau, P. M. 1964. Exchange and power in social life. New York: J. Wiley.

Bolton, P., \& Scharfstein, D. S. 1996. Optimal debt structure and the number of creditors. Journal of Political Economy, 104(1): 1-25.

Boot, A. W. A., \& Thakor, A. V. 2000. Can relationship banking survive competition? Journal of Finance, 55(2): 679-713.

Bound, J., Jaeger, D. A., \& Baker, R. M. 1995. Problems with instrumental variables estimation when the correlation between the instruments and the endogeneous explanatory variable is weak. Journal of the American Statistical Association, 90(430): 443-450.

Bresnahan, T. F., Gambardella, A., \& Saxenian, A. 2001. 'old economy' inputs for 'new economy' outcomes: Cluster formation in the new silicon valleys. Industrial $\mathcal{E}$ Corporate Change, 10(4): 835-860.

Burt, R. S. 1993. The social structure of competition. In R. Swedberg (Ed.), Explorations in economic sociology: 65-103. New York: Russell Sage Foundation.

Burt, R. S. 2002. The social capital of structural holes. In M. F. Guillen, \& et al. (Eds.), The new economic sociology: Developments in an emerging field: 148-190. New York: Russell Sage Foundation.

Dewatripont, M., \& Tirole, J. 1994. A theory of debt and equity: Diversity of securities and manager-shareholder congruence. The Quarterly Journal of Economics, 109(4): 1027-1054. 
Dore, R. 1983. Goodwill and the spirit of market capitalism. British Journal of Sociology, 34: 459-482.

Emerson, R. M. 1972. Exchange theory. Part 2 - exchange relations and networks. In J. Berger, M. J. Zelditch, \& B. Anderson (Eds.), Sociological theories in progress, Vol. 2: 58-87. Boston, MA: Houghton-Mifflin.

Evans, D. S., \& Jovanovic, B. 1989. An estimated model of entrepreneurial choice under liquidity constraints. Journal of Political Economy, 97(4): 808-827.

Goffman, E. 1959. The presentation of self in everyday life. New York: Anchor Books.

Gompers, P., \& Lerner, J. 2000. Money chasing deals? The impact of fund inflows on private equity valuations. Journal of Financial Economics, 55(2): 281-325.

Gompers, P. A. 1995. Optimal investment, monitoring, and the staging of venture capital. Journal of Finance, 50(5): 1461-1489.

Granovetter, M. 1985. Economic action and social structure: The problem of embeddedness. American Journal of Sociology, Vol 91(3): 481-510. Univ of Chicago Press, US.

Granovetter, M. 2000. A theoretical agenda for economic sociology. In M. F. Guillen, R. Collins, P. England, \& M. Meyer (Eds.), Economic sociology at the milllenium. NY: Russell Sage Foundation.

Gulati, R., \& Gargiulo, M. 1999. Where do interorganizational networks come from? American Journal of Sociology, Vol 104(5): 1439-1493. Univ of Chicago Press, US.

Hackman, J. R. 1987. The design of work teams. In J. W. Lorsch (Ed.), Handbook of organizational behavior: 315-342. Englewood Cliffs, NJ: Prentice-Hall.

Hannan, M. T., \& Carroll, G. R. 1992. Dynamics of organizational population: Density, legitimation, and competition. New York: Oxford University Press.

Hirschman, A. O. 1982. Rival interpretations of market society: Civilizing, destructive, or feeble? Journal of Economic Literature, 20(4): 1463-1484.

Ingram, P., \& Roberts, P. W. 2000. Friendships among competitors in the sydney hotel 
industry. American Journal of Sociology, Vol 106(2): 387-423. Univ of Chicago Press, US.

Kaplan, S. N., \& Schoar, A. forthcoming. Private equity performance: Returns, persistence, and capital flows. Journal of Finance.

Larson, A. 1992. Network dyads in entrepreneurial settings: A study of the governance of exchange relationships. Administrative Science Quarterly, 37(1): 76-104.

Locke, R. M. 2001. Building trust. Paper presented at the Annual Meetings of the American Political Science Association, SF.

Molm, L. D., Takahashi, N., \& Peterson, G. 2000. Risk and trust in social exchange: An experimental test of a classical proposition. American Journal of Sociology, Vol 105(5): 1396-1427. Univ of Chicago Press, US.

Podolny, J. M. 1994. Market uncertainty and the social character of economic exchange. Administrative Science Quarterly, 39(3): 458-483.

Podolny, J. M. 1993. A status-based model of market competition. American Journal of Sociology, 98(4): 829-872.

Podolny, J. M., Stuart, T. E., \& Hannan, M. T. 1996. Networks, knowledge, and niches: Competition in the worldwide semiconductor industry, 1984-1991. American Journal of Sociology, 102(3): 659-689.

Polanyi, K. 1944. The great transformation. Boston, MA: Beacon Press.

Shleifer, A. 2004. Does competition destroy ethical behavior? American Economic Review, 94(2).

Sobel, M. E. 1982. Asymptotic confidence intervals for indirect effects in structural equation models. In S. Leinhardt (Ed.), Sociological methodology: 290-312. Washington: Am. Sociological Assoc.

Stuart, T. E. 1998. Network positions and propensities to collaborate: An investigation of strategic alliance formation in a high-technology industry. Administrative Science Quarterly, Vol 43(3): 668-698. Administrative Science Quarterly, US.

Thibaut, J. W., \& Kelley, H. H. 1959. The social psychology of groups. NY: Wiley. 
Tirole, J. 1988. The theory of industrial organization. Cambridge, MA: MIT Press.

Uzzi, B. 1997. Social structure and competition in interfirm networks: The paradox of embeddedness. Administrative Science Quarterly, Vol 42(1): 35-67. Administrative Science Quarterly, US.

Uzzi, B. 1996. The sources and consequences of embeddedness for the economic performance of organizations: The network effect. American Sociological Review, 61(4): 674 .

Uzzi, B., \& Lancaster, R. 2003. Relational embeddedness and learning: The case of bank loan managers and their clients. Management Science, 49(4): 383. 